\title{
Sapotaceae endémicas del Perú
}

\author{
Blanca León ${ }^{1,2}$
}

${ }^{1}$ Museo de Historia Natural,
Av. Arenales 1256, Aptdo.
14-0434, Lima 14, Perú
${ }^{2}$ Plant Resources Center,
University of Texas at
Austin, Austin TX 78712
EE.UU.
blanca.leon@mail.utexas.edu

\section{Resumen}

La familia Sapotaceae es reconocida en el Perú por presentar 10 géneros y 90 especies (Brako \& Zarucchi, 1993; Ulloa Ulloa et al., 2004), todas árboles. En este trabajo reconocemos ocho especies endémicas en cuatro géneros. Pouteria es el género más rico en especies. Los taxones endémicos provienen de las regiones Bosques Muy Húmedos Premontanos, Bosques Muy Húmedos Montanos, Bosques Húmedos Amazónicos y Mesoandina, entre los 100 y $2500 \mathrm{~m}$ de altitud. Una especie endémica se encuentra representada dentro del Sistema Nacional de Áreas Naturales Protegidas por el Estado.

Palabras claves: Sapotaceae, Pouteria, Perú, endemismo, plantas endémicas.

\section{Abstract}

The Sapotaceae are represented in Peru by 10 genera and 90 species (Brako \& Zarucchi, 1993; Ulloa Ulloa et al., 2004), all trees. Here we recognize eight endemic species in four genera. Pouteria is the genus with more endemic species. Endemic species are found in Very Humid Premontane Forests, Humid Lowland Amazonian Forests, Very Humid Montane Forests and Mesoandean regions, between 100 and 2500 m elevation. One endemic species has been recorded within Peru's protected areas system.

Keywords: Sapotaceae, Pouteria, Peru, endemism, endemic plants.

\section{Chrysophyllum contumacense Sagást. \& M.O. Dillon}

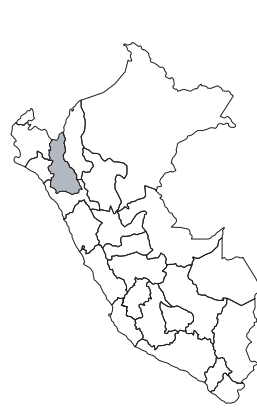

\section{DD} 14817

Herbarios: F; $\underline{\mathrm{HAO}}$.

Nombre común: Gashmin.

Registro departamental: CA.

Regiones Ecológicas: MA; $2500 \mathrm{~m}$.

SINANPE: Sin registro.
Publicación: Arnaldoa 8(2): 57-58. 2001. Colección tipo: A. Sagástegui A. \& S. Leiva

Herbarios peruanos: HAO (holotipo citado).

Observaciones: Árbol conocido del norte de la vertiente del Pacífico. Esta entidad fue originalmente denominada Chrysophyllhum edule, pero este nombre ya había sido empleado para otra especie. Chrysophyllum contumacense tiene frutos comestibles. Se desconoce el estado actual de sus poblaciones.

\section{Chrysophyllum revolutum Mart. \& Eichler}

DD

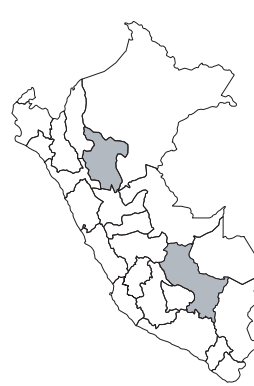

Publicación: Fl. Bras. 7: 104. 1863.

Colección tipo: R. Spruce 4260

Herbarios: BM, BR, F, G, GH, GOET, K, NY, OXF, P, W.

Nombre común: Desconocido.

Registro departamental: CU, SM.

Regiones Ecológicas: BMHP; 750—1200 $\mathrm{m}$.

SINANPE: Sin registro.

Herbarios peruanos: Ninguno.

Observaciones: Árbol bajo, conocido de poblaciones dispersas, en bosques amazónicos. El ejemplar tipo fue recolectado en el siglo XIX, de la cuenca del Mayo. Otras poblaciones, aparentemente, disyuntas son conocidas entre las cuencas del Yanatili y Urubamba. Se desconoce el estado actual de sus poblaciones.

\section{Micropholis macrophylla (Krause) T.D. Penn.}

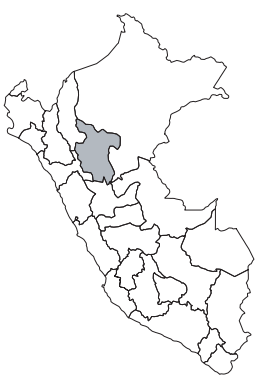

\section{EN, B1a}

Publicación: Fl. Neotrop. 52: 225. 1990.

Colección tipo: E.H.G. Ule 6793

Herbarios: G, K, MG.

Nombre común: Desconocido.

Registro departamental: SM.

Regiones Ecológicas: BMHP; $1200 \mathrm{~m}$.

SINANPE: ACRCE

Herbarios peruanos: Ninguno.

Observaciones: Árbol conocido aparentemente sólo de la localidad tipo, en el departamento de San Martín, si bien fue reportada erroneamente por Brako \& Zarucchi (1993) como de Loreto. Esta especie fue descrita de una planta recolectada en 1903 de las laderas de Cerro La Escalera, hoy reconocida en el Area de Conservación Regional Cerro La Escalera. Esta localidad alberga varios otros endemismos; sin embargo, no ha sido herborizada en detalle.

\section{Pouteria bonneriana Bernardi}

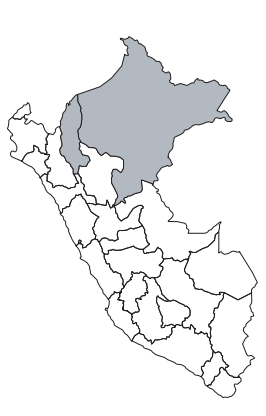

\section{EN, B1a}

Publicación: Candollea 22: 237, f. k-q. 1968.

Colección tipo: J.J. Wurdack 2514

Herbarios: G, K, NY, US.

Nombre común: Desconocido.

Registro departamental: AM, LO.

Regiones Ecológicas: BHA; $300-450 \mathrm{~m}$.

SINANPE: Sin registro.

Herbarios peruanos: Ninguno.

Observaciones: Árbol conocido, al parecer, de dos ejemplares de herbario (Pennington, 1990), ambos recolectados de la cuenca del Santiago, en las faldas de Cerro Campanquiz, una zona de interés para la biología y conservación, por que asociado a su aislamiento de la cordillera oriental andina, incluye varios otros endemismos, los que no han sido recolectados desde 1962. Probable amenaza a esta especie podría ser la deforestación asociada a colonización. 


\section{Pouteria cinnamomea Baehni}

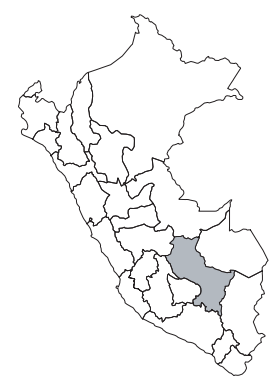

EN, B1ab(iii)

Publicación: Candollea 9: 252. 1942.

Colección tipo: A. Weberbauer 5034

Herbarios: B.

Nombre común: Jabajaba.

Registro departamental: CU.

Regiones Ecológicas: BMHM; $1700 \mathrm{~m}$.

SINANPE: Sin registro.

Herbarios peruanos: Ninguno.

Observaciones: Árbol conocido solamente del ejemplar tipo, una planta recolectada en 1905, en la cordillera de Vilcabamba, entre las cuencas del Urubamba y Apurímac. La localidad original ha sido escasamente herborizada, siendo de preocupación la deforestación.

\section{Pouteria pisquiensis Baehni}

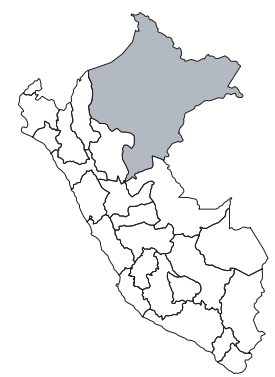

\section{DD}

Publicación: Candollea 9: 263. 1942.

Colección tipo: G. Tessmann 3103

Herbarios: F, G, NY.

Nombre común: Desconocido.

Registro departamental: LO.

Regiones Ecológicas: BHA; $150 \mathrm{~m}$.

SINANPE: Sin registro.

Herbarios peruanos: Ninguno.

Observaciones: Especie arbórea conocida de la cuenca del Pisqui, un tributario del Ucayali, localizado en el sur del Departamento de Loreto. Al parecer, no ha vuelto a ser recolectada desde 1923 (Pennington, 1990). Se desconoce el estado actual de sus poblaciones.

\section{Pouteria sessilis T.D. Penn.}

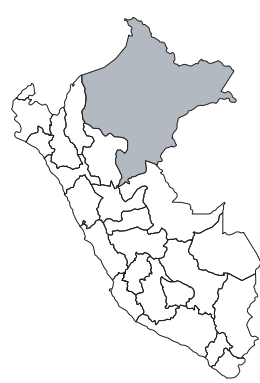

\section{DD}

Publicación: Fl. Neotrop. 52: 327, f. 69CD. 1990.

Colección tipo: L. Bernardi s.n.

Herbarios: G.

Nombre común: Desconocido.

Registro departamental: LO.

Regiones Ecológicas: BHA; 100—200 m. SINANPE: Sin registro.

Herbarios peruanos: Ninguno.

Observaciones: Árbol descrito de una planta recolectada en el Arboreto Jenaro Herrera. Se desconoce el estado actual de sus poblaciones.

\section{Pradosia argentea (Kunth) T.D. Penn.}

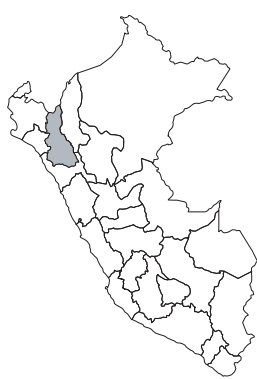

\section{DD}

Publicación: Fl. Neotrop. 52: 660—661. 1990.

Colección tipo: A. Humboldt \& A. Bonpland s.n.

Herbarios: P.

Nombre común: Desconocido.

Registro departamental: CA.

Regiones Ecológicas: Sin datos; altitud desconocida.

SINANPE: Sin registro.

Herbarios peruanos: Ninguno.

Observaciones: Especie arbórea, descrita de una planta recolectada en 1802, de una localidad, Jaén de Bracamoros, probablemente localizada en la cuenca del Chamaya, cerca al Marañón. Se desconoce el estado actual de sus poblaciones. 